NASA/TM-2005-213898

Numerical Prediction of Non-Reacting and Reacting Flow in a Model Gas Turbine Combustor

Farhad Davoudzadeh

University of Toledo, Toledo, Ohio

Nan-Suey Liu

Glenn Research Center, Cleveland, Ohio 
Since its founding, NASA has been dedicated to the advancement of aeronautics and space science. The NASA Scientific and Technical Information (STI) Program Office plays a key part in helping NASA maintain this important role.

The NASA STI Program Office is operated by Langley Research Center, the Lead Center for NASA's scientific and technical information. The NASA STI Program Office provides access to the NASA STI Database, the largest collection of aeronautical and space science STI in the world. The Program Office is also NASA's institutional mechanism for disseminating the results of its research and development activities. These results are published by NASA in the NASA STI Report Series, which includes the following report types:

- $\quad$ TECHNICAL PUBLICATION. Reports of completed research or a major significant phase of research that present the results of NASA programs and include extensive data or theoretical analysis. Includes compilations of significant scientific and technical data and information deemed to be of continuing reference value. NASA's counterpart of peerreviewed formal professional papers but has less stringent limitations on manuscript length and extent of graphic presentations.

- TECHNICAL MEMORANDUM. Scientific and technical findings that are preliminary or of specialized interest, e.g., quick release reports, working papers, and bibliographies that contain minimal annotation. Does not contain extensive analysis.

- CONTRACTOR REPORT. Scientific and technical findings by NASA-sponsored contractors and grantees.
- CONFERENCE PUBLICATION. Collected papers from scientific and technical conferences, symposia, seminars, or other meetings sponsored or cosponsored by NASA.

- SPECIAL PUBLICATION. Scientific, technical, or historical information from NASA programs, projects, and missions, often concerned with subjects having substantial public interest.

- TECHNICAL TRANSLATION. Englishlanguage translations of foreign scientific and technical material pertinent to NASA's mission.

Specialized services that complement the STI Program Office's diverse offerings include creating custom thesauri, building customized databases, organizing and publishing research results ... even providing videos.

For more information about the NASA STI Program Office, see the following:

- Access the NASA STI Program Home Page at http://www.sti.nasa.gov

- E-mail your question via the Internet to help@sti.nasa.gov

- Fax your question to the NASA Access Help Desk at 301-621-0134

- Telephone the NASA Access Help Desk at 301-621-0390

- Write to:

NASA Access Help Desk

NASA Center for AeroSpace Information 7121 Standard Drive

Hanover, MD 21076 
NASA/TM-2005-213898

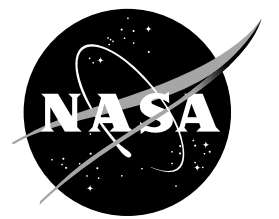

Numerical Prediction of Non-Reacting and Reacting Flow in a Model Gas Turbine Combustor

Farhad Davoudzadeh

University of Toledo, Toledo, Ohio

Nan-Suey Liu

Glenn Research Center, Cleveland, Ohio

Prepared for the

Turbo Expo 2004

sponsored by the American Society of Mechanical Engineers

Vienna, Austria, June 14-17, 2004

National Aeronautics and

Space Administration

Glenn Research Center 


\section{Acknowledgments}

The NASA Ultra Efficient Engine Technology (UEET) program has supported this work. The authors greatly appreciate the advice, help, and useful suggestions that they received from Jeff Moder and Ananda Himansu during the course of this research. Furthermore, the authors are grateful to Chris Edward and Thomas Bowman for providing the experimental data. The computer cluster used was SGI Origin 3000 located at NAS, NASA Ames Research Center.

Available from

NASA Center for Aerospace Information 7121 Standard Drive

Hanover, MD 21076
National Technical Information Service 5285 Port Royal Road Springfield, VA 22100 


\title{
Numerical Prediction of Non-Reacting and Reacting Flow in a Model Gas Turbine Combustor
}

\author{
Farhad Davoudzadeh \\ University of Toledo \\ Toledo, Ohio 43606 \\ Nan-Suey Liu \\ National Aeronautics and Space Administration \\ Glenn Research Center \\ Cleveland, Ohio 44135
}

\section{ABSTRACT}

The three-dimensional, viscous, turbulent, reacting and non-reacting flow characteristics of a model gas turbine combustor operating on air/methane are simulated via an unstructured and massively parallel Reynolds-Averaged Navier-Stokes (RANS) code. This serves to demonstrate the capabilities of the code for design and analysis of real combustor engines. The effects of some design features of combustors are examined. In addition, the computed results are validated against experimental data.

The numerical model encompasses the whole experimental flow passage, including the flow development sections for the air annulus and the fuel pipe, twelve channel air and fuel swirlers, the combustion chamber, and the tail pipe. A cubic non-linear low-Reynolds number K-e turbulence model is used to model turbulence, whereas the eddy-breakup model of Magnussen and Hjertager is used to account for the turbulence combustion interaction. Several RANS calculations are performed to determine the effects of the geometrical features of the combustor, and of the grid resolution on the flow field. The final grid is an all-hexahedron grid containing approximately two and one half million elements.

To provide an inlet condition to the main combustion chamber, consistent with the experimental data, flow swirlers are adjusted along the flow delivery inlet passage.

Fine details of the complex flow structure such as helicalring vortices, recirculation zones and vortex cores are well captured by the simulation. Consistent with the experimental results, the computational model predicts a major recirculation zone in the central region immediately downstream of the fuel nozzle, a second recirculation zone in the upstream corner of the combustion chamber, and a lifted flame. Further, the computed results predict the experimental data with reasonable accuracy for both the cold flow and for the reacting flow. It is also shown that small changes to the geometry can have noticeable effects on the combustor flowfield.

\section{INTRODUCTION}

Computational fluid dynamics (CFD) has become an integral part in the design process of aeropropulsion engines, and a viable tool in understanding complex physical features of flowfields associated with various components of these engines. Use of CFD allows experimentation with new innovative design ideas that was not possible before, due to the excessive cost associated with manufacturing and testing of the prototypes. Thus CFD is able to improve design, reduce development cost, contribute to improved performance, and increase understanding of flowfield induced in yet not fabricated configurations.

In particular, gas turbine combustion modeling involves many complex physical processes that occur simultaneously such as combustion, turbulence, turbulence chemistry interaction, reaction kinetics, turbulence spray interaction, heat transfer, and radiation. In addition to solving the ReynoldsAveraged Navier-Stokes equations with a turbulence model, one may need to solve tens of individual species mass balance. The required partial differential equations to be solved could easily add up to 30 to 40 equations, depending on the number of species involved in the reaction kinetics. Considering various physical processes that are modeled and the resolution required for the grid to resolve scales of these processes, computational resources needed may become extensive and costly. In addition the complexities of the geometries of the combustors raise the daunting task of curvilinear grid generation.

However, to apply CFD in real-world design applications, the complex 3-D geometries, and many of the physical processes involved need to be resolved. With decreasing computing cost, increasing CPU speed, and the development of the parallel computing platform, computational cost and time is reduced to a level that fit in the design cycle time frame. Furthermore, with the advance of the numerical schemes using unstructured or Chimera meshes, mesh generation is becoming less intimidating than it used to be. The major task still remains 
to be the development of the schemes and models that address the physics involved and take advantage of the parallel computing.

Ultimately, the proof of validity of any numerical model lies in how well it represents the physics involved in the combustion process within given boundaries and with certain inlet and exit boundary conditions. CFD codes and combustion models developed for gas turbine applications need to be validated against experimental combustor tests with properly characterized inflow conditions, realistic combustion conditions, and detailed velocity and chemical species measurements.

The work described in this paper is a RANS simulation of an experimental gas turbine combustor, and tries to address many of the issues raised above. The gas turbine combustor modeled here is designed to create a lifted and stable flame. Extensive experimental velocity, temperature and chemical species data are provided from the experiment for evaluation and validation of the CFD codes.

The simulation is performed for both non-reacting flow and reacting flow.

\section{COMPUTATIONAL METHOD:}

The computational work performed to produce the numerical results presented in this paper uses the National Combustion Code (NCC), developed at NASA Glenn Research Center (GRC) for comprehensive modeling and simulation of aerospace combustion systems.

The focus in the development of the integrated system of computer codes has been to calculate the fluid, thermal, and chemical characteristics of real-world combustors to an appropriate level of accuracy and turnaround time desired by designers and analysts. The two foremost important obstacles to turnaround time have been grid generation and serial processing.

Use of unstructured or overset grids and parallel computing minimizes the overall time needed to achieve a numerical solution. Thus the main focus has been to incorporate a numerical scheme that allows use of a large number (thousands) of processors in parallel to shorten the solution time and to provide speed-ups that does not deteriorate with the addition of more processors.

The main flow solver for the code used in this work is based on an explicit four-stage Runge-Kutta scheme, which is very suitable for parallelization. Figure 1 shows an example of the speedup that has been achieved with the code on an SGI Origin 2000 [1]. This 3-D test case uses 1.3 million tetrahedral elements for simulation of a premixed hydrogen/air combustor [2], using the Intrinsic Low Dimensional Manifold (ILDM) kinetics module $[3,4]$. The parallel speedup metric is calculated by taking the ratio of the time per iteration for the serial case versus the time per iteration for the parallel case. The parallel efficiency is the ratio of the parallel speedup to the number of processors used in the calculation. In the calculations presented in this paper, the authors increased the number of processors from 200 to 400 and achieved approximately a factor of two speedup for a 2.5 million elements domain.

To facilitate the grid generation task, the code is designed to use unstructured meshes. It uses triangular and/or quadrilateral elements in the 2-D cases, and tetrahedrons, wedges, pyramids, and hexahedrons in the 3-D cases. A combination of these grid types can be used to create hybrid grids. For example, to resolve the boundary layer one may choose to use hexahedron elements in the wall region and transition out of the boundary layer to tetrahedron elements via pyramid elements.

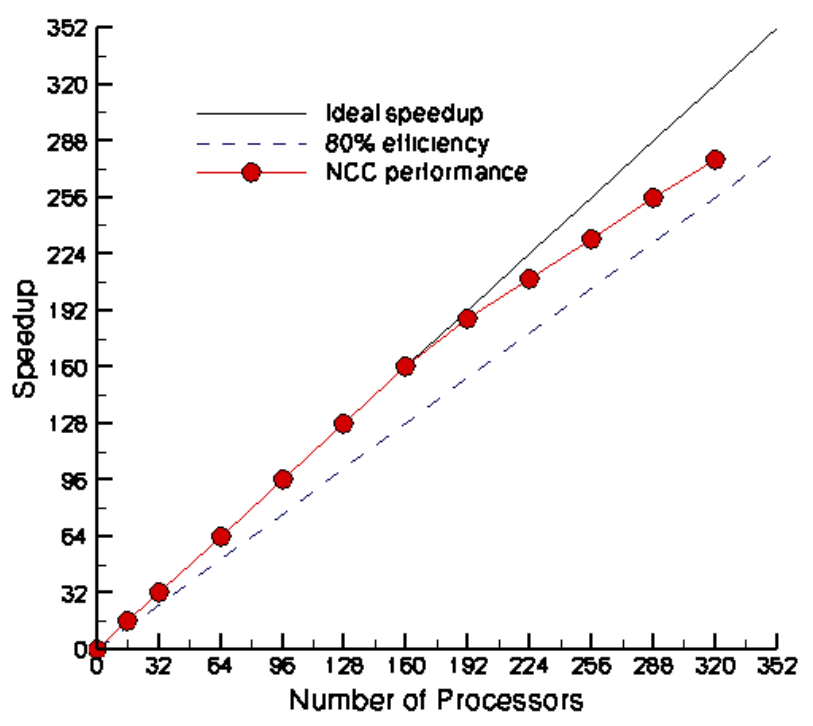

Fig 1. Speedup curve for the $1.3 \mathrm{M}$ element test case (Quealy, 2002 [1])

In brief, the flow solver solves unsteady, 3-D, compressible Navier-Stokes equations. The discretization begins by dividing the computational domain into a large number of elements, which can be of mixed types. A centraldifference finite-volume scheme augmented with numerical dissipation is used to generate the discretized equations, which are then advanced temporally by an explicit 4-stage RungeKutta scheme. For low Mach number compressible flow, a preconditioning is applied to the governing equations, and the solution is advanced temporally by a so-called "dual-timestep" approach, in which the Runge-Kutta scheme is used for the "inner" iteration. The turbulence model used in the present work is a cubic non-linear k-epsilon model [5] with low Reynolds number wall integration. This turbulence model is reported [5] to capture the recirculation zones and their structures with more accuracy, relative to the standard k-epsilon model. A description of the solver and some benchmark test cases can be found in Refs. [6-7].

\section{EXPERIMENTAL SETUP AND THE GEOMETRY}

The schematic of the experimental model gas turbine combustor operating on air/methane is shown in Fig. 2. The experimental work is performed by Bowman and Edwards [9]. The operating condition of the gaseous combustor is also summarized in Fig. 2. The overall combustor assembly consists of three distinct sections: fuel delivery, main combustion chamber, and a tailpipe. Flow is delivered through two separate co-annular concentric pipes. The low velocity methane fuel is delivered through the inner pipe, whereas the higher velocity air is delivered through the annulus of the two pipes. Both fuel and airflows pass through $45^{\circ}$ helical co-swirling swirlers located at 3.33D upstream of the combustor inlet and become highly swirling flows as they enter the main combustion chamber $(\mathrm{D}=146 \mathrm{~mm}$ is the diameter of the combustion 


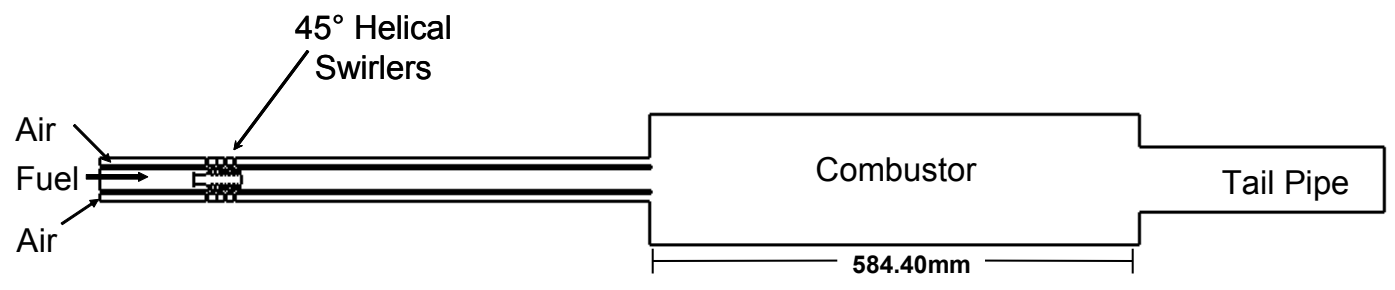

\begin{tabular}{|l|c|c|c|}
\hline $\begin{array}{c}\text { Equivalence ratio } \\
\boldsymbol{\Phi}=0.67 \pm 0.02\end{array}$ & $\begin{array}{c}\text { Mass flow rate } \\
\mathbf{g} / \mathbf{s}\end{array}$ & $\begin{array}{c}\text { Mean velocity } \\
\mathbf{m} / \mathbf{s}\end{array}$ & Rey \# \\
\hline Air & $30.7 \pm 0.5$ & 23 & $\begin{array}{c}14000 \\
\text { (based on gap height) }\end{array}$ \\
\hline Methane & $1.20 \pm 0.02$ & 3.9 & $\begin{array}{c}5800 \\
\text { (based on diameter) }\end{array}$ \\
\hline
\end{tabular}

Fig. 2. Axial cross section and operating condition of the gaseous combustor operating on methane fuel

chamber). This is necessary for creating a lifted, stable flame and for good mixing of the reactants. To facilitate LDV measurements, the fuel tube protrudes by a length of D/60 into the combustion chamber. Forced convective cooling is provided along the length of the test section from a concentric air shroud surrounding the test section.

The tail-pipe section provides a positive pressure gradient to inhibit formation of long vortex cores that ingest air from the exit of the combustor.

Figure 3 shows the close-up of the $45^{\circ}$ helical co-swirling swirlers. Figure $3 \mathrm{a}$, shows the experimental air swirler. The fuel swirler cannot be seen in Fig. 3a, since the air swirler and the fuel tube mask it. Figure $3 b$, shows the digitized model of the experimental swirlers. In the digitized model, both the air swirler and the fuel swirler can be observed. Each swirler consists of 12 curved channels. So, all together there are 24 curved channels, 12 for swirling the fuel flow and 12 for swirling the airflow.

\section{COMPUTATIONAL DOMAIN AND THE MESH:}

The numerical simulation is performed for the whole geometry including the flow development sections for the air annulus and the fuel pipe, 24-channel air and fuel swirlers, the combustor, and the tail pipe. A total of 2,479,352 hexahedrononly elements are used of which 1,094,356 are used in the flow delivery tubes, $1,220,698$ in the combustion chamber, and 164,298 in the tail pipe. In contrast to grid topologies where the centerline becomes the axis of singularity around which wedge type elements are generated, in this all-hexahedron mesh, there is no axis of singularity (see Fig. 5), and as seen in Fig. 4, the boundary layer is well resolved, with $\mathrm{y}^{+}<1.0$.

Figure 4 shows the grid distribution used for the gaseous combustor simulation. In this figure the fuel tube protruding into the combustion chamber can be seen. The air flows through the annulus of the two tubes. The grid distribution on the swirlers is shown in Fig. 6. The center hub upon which the fins of the fuel swirler are mounted is also shown in the figure.

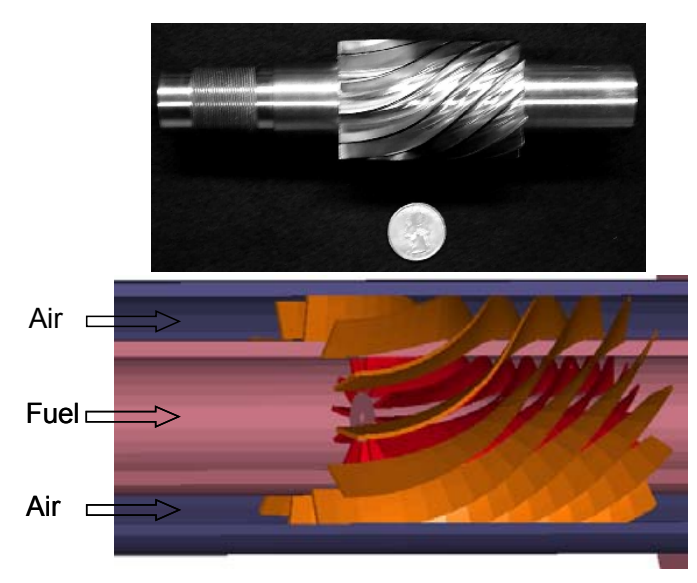

(a)

Fig. 3. Air and fuel swirlers

(a) Hardware

(b) Computational model

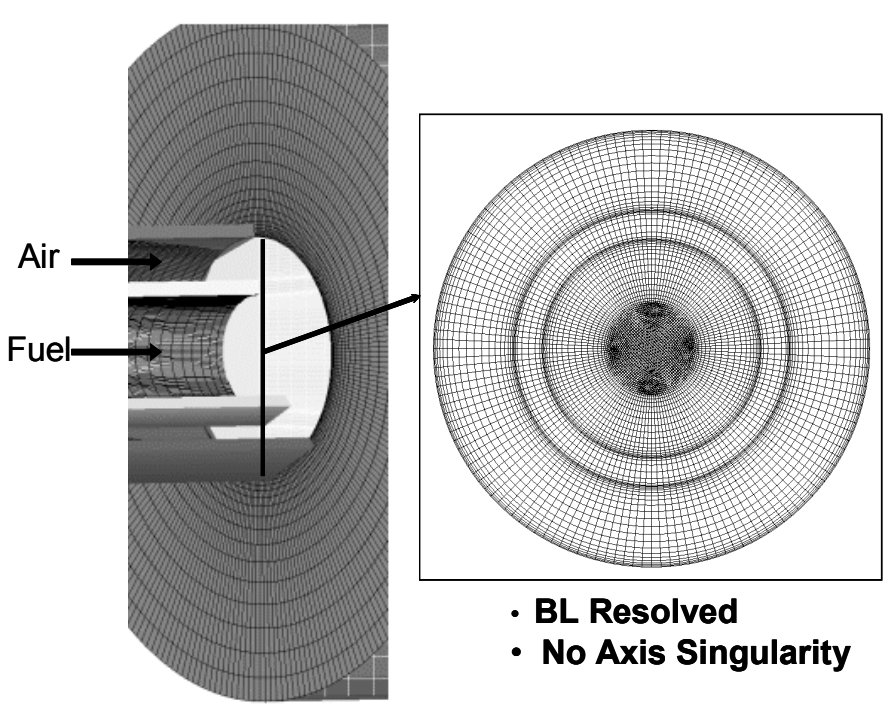

Fig. 4. Gas-phase Combustor Hex-only Mesh 


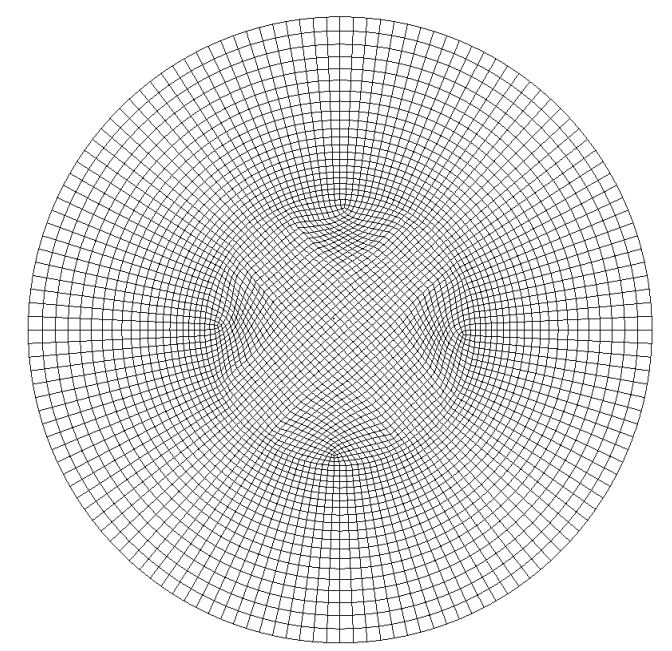

- Hex-only Mesh

- No Axis Singularity

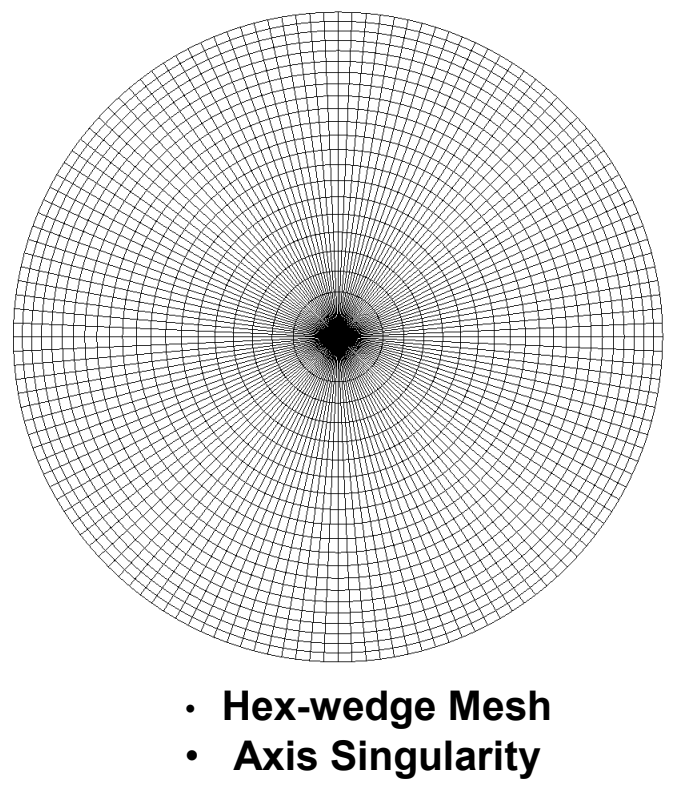

Fig. 5. Centerline region grid topologies

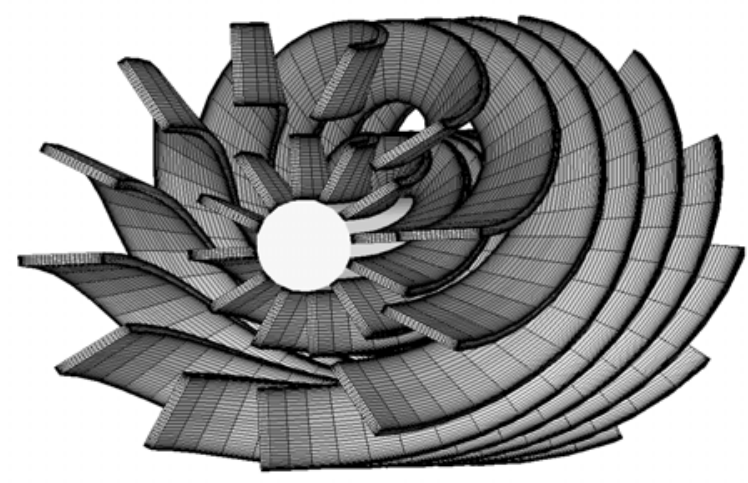

Fig. 6. Grid distribution on the swirlers

\section{NUMERICAL SIMULATION:}

The numerical simulations solve the Reynolds-Averaged Navier-Stokes equations on an unstructured discretization with turbulence, chemical species, and combustion models. Turbulence is modeled by a cubic non-linear k-epsilon model with low Reynolds number wall integration [5]. The chemistryturbulence interactions are represented by the eddy-dissipation combustion model of Magnussen and Hjertager [8], where combustion rate is assumed to be controlled by the turbulence mixing rate of the reactants. It should be mentioned that other combustion models such as scalar probability density function (PDF) together with finite rate chemical kinetics are available in the code. These models are more complex and costly; consequently in the present study the more simplified model of the eddy breakup concept is used.

The chemistry model used is the one-step global kinetics having species fuel (CH4), oxidant (air), and products. The absence of the intermediate species, such as $\mathrm{OH}$ leads to overprediction of temperature, especially in fuel-rich regions. This effect manifested itself in the temperature predictions presented in the reacting flow simulation section.

Inlet boundary condition specifies flow speed normal to the inlet face, density, turbulence intensity level, turbulence mixing length, static temperature, and inlet mass fractions for the species. The inlet condition for the reacting flow and the nonreacting flow are similar.

The exit boundary condition specifies static pressure. For the subsonic exit flow, velocity components, enthalpy, turbulent kinetic energy, dissipation rate, and species mass fractions are extrapolated from the interior of the domain.

\section{GEOMETRY AND GRID EFFECTS:}

A key feature in combustor design is the control of the mixing of the reactants and the stability of the flame in the combustion region, via creation of recirculation zones. Short compact combustion flames are supposed to reduce hazardous product species such as NOx. In the following section, effects of some modifications to the original features of the geometry are examined.

The first feature to examine is protrusion of the fuel nozzle into the combustion chamber. As described earlier in the description of the geometry, the fuel nozzle is configured to protrude slightly into the combustion chamber. Two computations are performed to examine the effect of this feature. In the first calculation, the fuel tube is not protruded and is flush with the inlet plane, whereas in the second configuration the protrusion is maintained. Both these calculations are run for the full 3-D geometry, non-reacting flow, and on almost identical coarse grids, each consisting of $1,323,264$ elements. The computational location of the swirlers, for these coarse grid computations, is the same as shown in Fig 8a. The sensitivity of the flowfield to the swirlers location is discussed later in this section.

Figure 7 shows the computed axial velocity contours for axial cross-section of the combustor for both configurations. Comparison of the two axial velocity contours shows that the small protrusion of the fuel tube into the testing section (Fig. 7a) appreciably influences on the development of the central recirculation zone. The size and the structure of the recirculation zones will have a significant affect on the mixing of the reactants and on the stability of the flame. The streaks in 


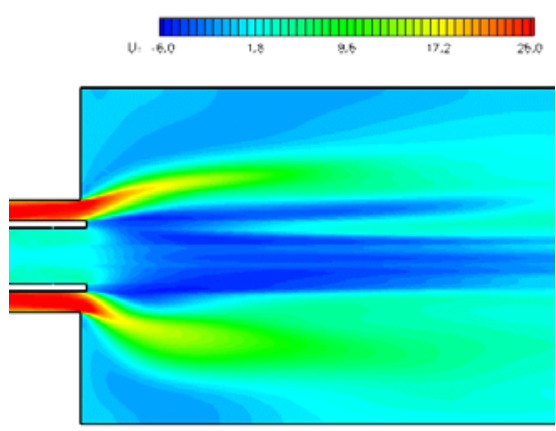

(a) Protruded fuel tube

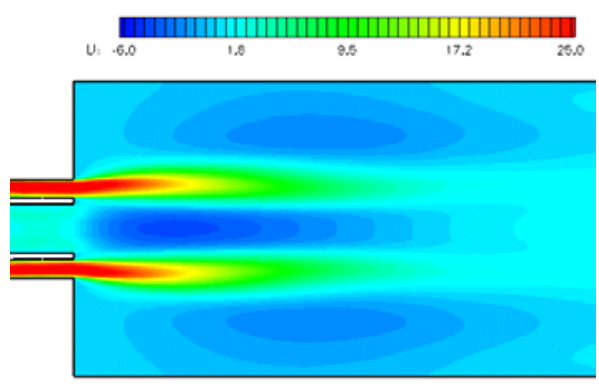

(b) Flush fuel tube

Fig. 7. Coarse grid, axial velocity component

the contours near the centerline in Fig. 7a, indicate that the flow is not sufficiently resolved by the grid. The rest of the computations reported in this paper are performed with a higher grid resolution and with the protrusion feature included in the geometry.

The second design feature examined is the proximity of the swirlers to the primary combustion zone. In the axial velocity contour plots shown in Fig. 8, swirlers are configured to be upstream of the combustor inlet plane by $0.33 \mathrm{D}$ in Fig. 8a, and by $1.22 \mathrm{D}$ in Fig. $8 \mathrm{~b}$. In both cases, the air jet spreads quickly toward the wall of the combustor and a recirculation zone is formed near the centerline. However, for the case in which the swirlers are closer to the combustion chamber the resulting recirculation zone is much larger in both radial and axial directions. And as evident by the zero axial velocity dashed contour lines, the computed recirculation zone spread farther upstream into the fuel tube. The strength in the swirl is increased as the swirlers are moved closer to the inlet, since there is less distance for dissipation. Figure 8 also shows the creation of additional recirculation zone in the corner region. These two recirculation zones in effect behave as a flame holder in the reacting calculation case presented later in this paper. Both of these computations are performed on fine grids of approximately 2.5 million elements each.

\section{RESULTS:}

In the following sections the computed results for the nonreacting case are presented first, followed by the reacting one. In each case the computed results are compared with the corresponding experimental data.

The simulation includes the detailed modeling of the entire system--rather than only a slice of the physical domain-including the swirlers passages. This will eliminate making assumptions for the flow to be necessarily either axisymmetric or periodic. Considering that no detailed experimental data

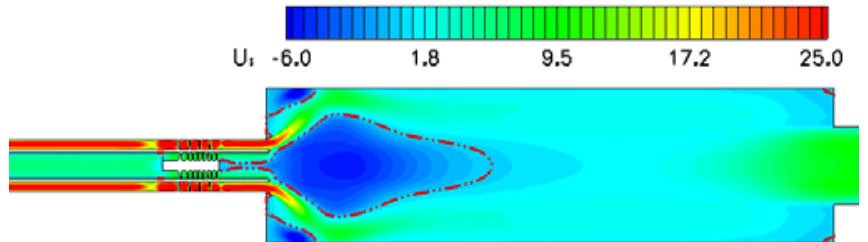

(a)

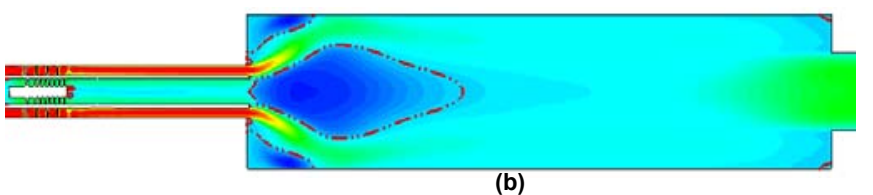

Fig. 8. Effect of swirlers' location on the flowfield Fine grid, axial velocity component

were taken at the inlet of the chamber, alternative approaches, such as eliminating the swirlers and assuming an inlet profile to the combustion chamber, would have introduced more uncertainty to the computation. The inclusion of the swirlers in the computational domain provides an overall more realistic inflow to the main combustion chamber.

It should be noted that in the experimental configuration, as shown in Fig. 2, the swirl generators are located far upstream of the main combustion chamber, an unlikely configuration in industrial combustors. As a result, the swirl decays in the inlet pipe. In addition to the physical decay of the swirl in the delivery tubes, the numerical dissipation, the turbulence model, and the grid resolution also contribute to the calculated decay of the swirl. To compensate for these numerical factors, in the simulation, the swirlers are moved closer to the main combustion chamber, to a location approximately 1.22D to the inlet of the combustion chamber, to create the best possible match between the predicted and the experimental velocity profiles at the first station of the measurement. Note that, except for the far upstream boundary condition, all the experimental measurements were taken inside the combustion chamber, but no experimental data were available to prescribe the inlet to the combustion chamber.

\section{NON-REACTING FLOW SIMULATION:}

The numerical iteration is carried out until a steady state is reached. The metric for the convergence of the iterations is the residual of the equations being solved. Typically, when the residuals of the momentum equations drop by more than three orders of magnitude, and there is no appreciable change in the solution, the case is considered as converged. The balance of the mass flux into and out of the computational domain is also monitored. When the convergence is reached, the mass balance is also achieved. In considering the above metrics, care should be given to the cases where a local unsteadiness may inhibit the residuals to drop significantly, even though the case may have reached global convergence.

The non-reacting flow simulation reveals the overall structure of the flowfield and show the mixing of the higher velocity air with the lower velocity methane. The intended swirl in the combustion chamber for the flame stability and good mixing of the reactants can also be examined.

Figure 9 is an axial cross-section showing the axial velocity component contours in the upper part, and the experimental and computational radial profiles below it. The 
solid black lines are computational results and the red diamond symbols are the experimental data. No experimental data is reported between $38.1 \mathrm{~mm}$ and $152.4 \mathrm{~mm}$ stations. It was reported in Ref. [9] that "the flow in this region was bistable and alternates between mean values at a sufficiently low frequency that it was considered impractical to attempt to sample this part of the flowfield over a sufficient period of time to obtain stable statistics [9]."

The computed radial profiles are averaged spatially in the azimuthal direction whereas, the experimental data are taken across the two radii on opposite sides of the center line and averaged in time. Here, the experimental data from both sides of the centerline are overlapped on each other and are shown as a function of radius; hence two points appearing at the same radial location are from radial locations on opposite sides of the centerline, mirroring one another.

Figure 9 compares all the reported experimental axial velocity values with the computed ones. It gives an overall view of the flow and of how well the measured and computed values match.

The axial velocity is strong at the inlet across the air-jet. This is not the case across the fuel jet, since the fuel flows with a lower velocity and the central re-circulation zone obstructs the free flow of the fuel jet into the combustion chamber.
The radial profile of the axial velocity at station $38.1 \mathrm{~mm}$ shows how fast the air jet spreads toward the wall of the combustor. This is also clear from the flooded contours shown on the top half.

The experimental data show emergence of an axial velocity jet close to the centerline downstream of the centerline recirculation zone. The simulation does not predict this central jet.

The overall axial velocity at all stations is predicted with reasonable accuracy.

Figure 10 is an axial cross-section showing the contours of the azimuthal velocity, as well as experimental and computational azimuthal profiles.

At station $\mathrm{x}=4.5 \mathrm{~mm}$, there is a strong azimuthal velocity across the air jet however, computational results indicate that this strong azimuthal velocity dies down rapidly towards the combustor's wall. In the experimental data, the azimuthal velocity still remains high past the air jet.

To evaluate the degree of accuracy with which the velocity components are computed, line plots at various axial stations showing radial profiles of the averaged axial and the averaged azimuthal velocities are given in Figs. 11-12. The horizontal bars are experimental velocity fluctuations about the mean and they are evaluated by the experimentalists [9] to represent the

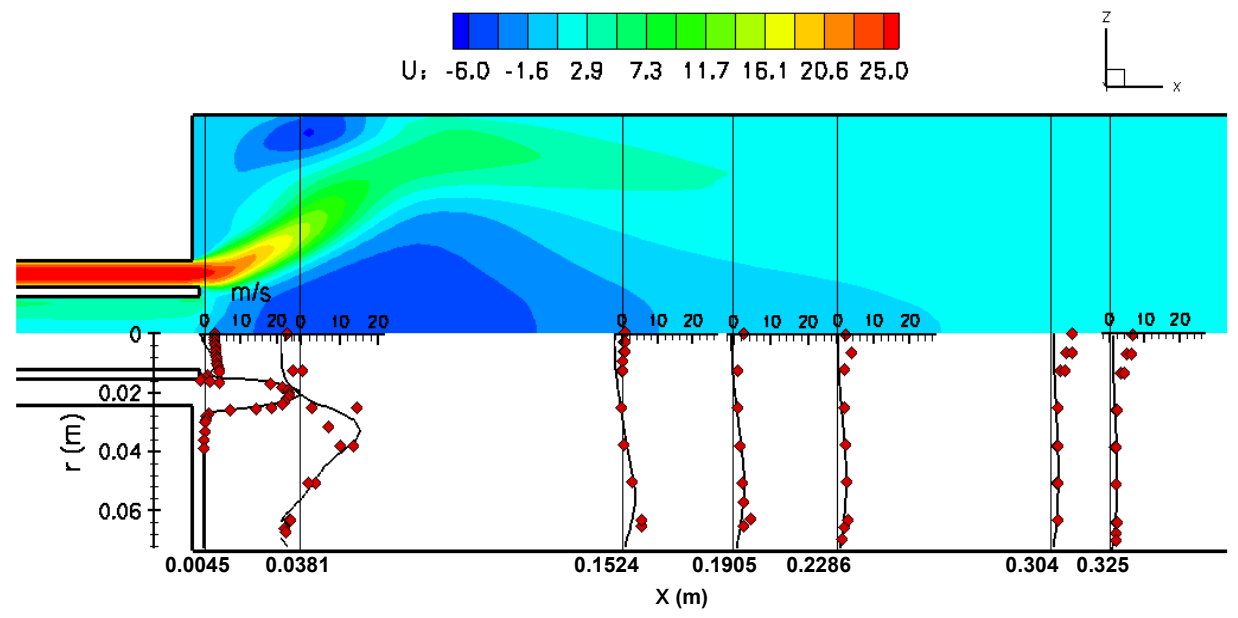

Fig. 9. Non-reacting flow: Axial velocity contours \& radial profiles

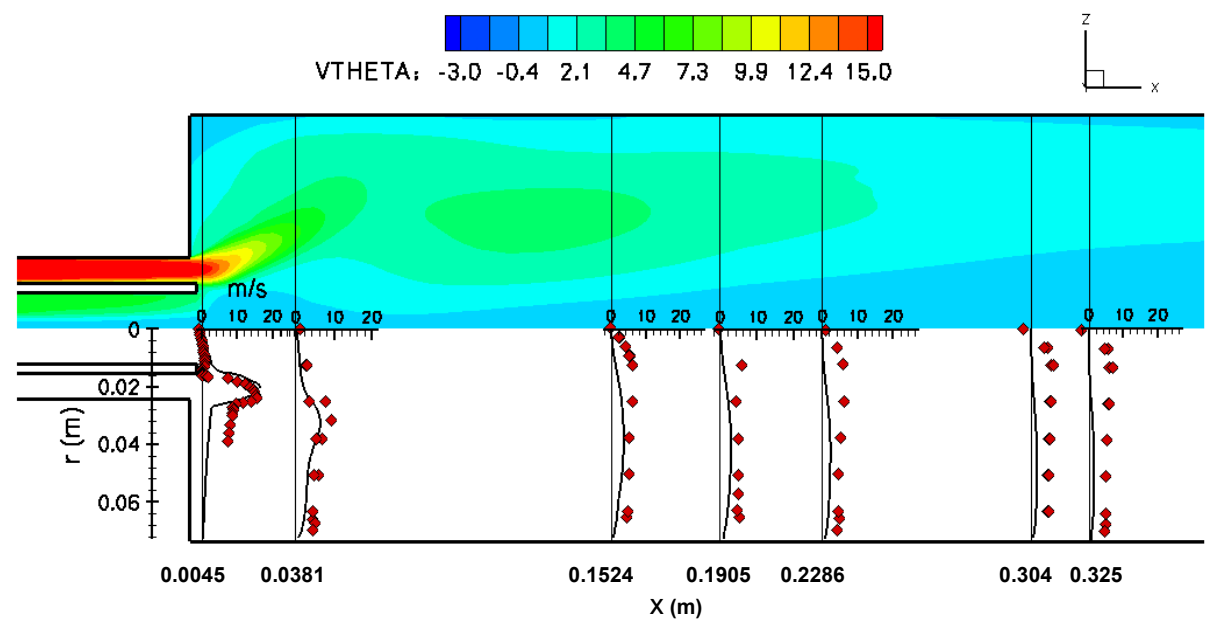

Fig. 10. Non-reacting flow: Azimuthal velocity contours $\&$ radial profiles 


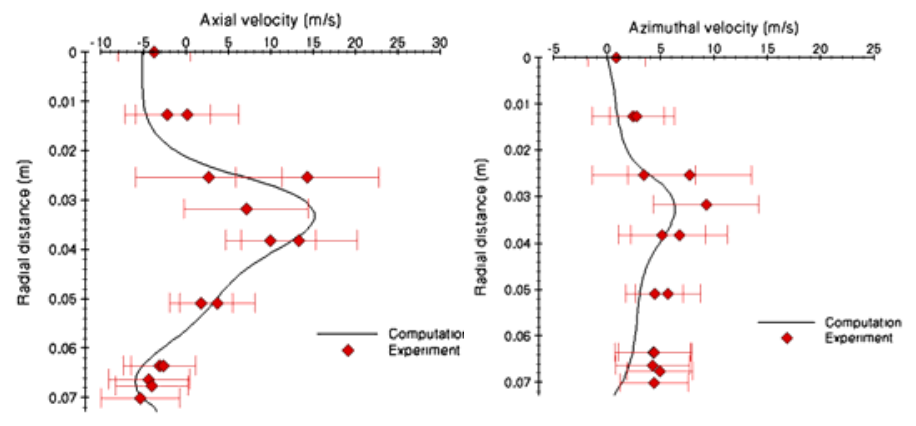

Fig. 11. Non-reacting Flow: Axial and azimuthal velocity components at $x=38.1 \mathrm{~mm}$
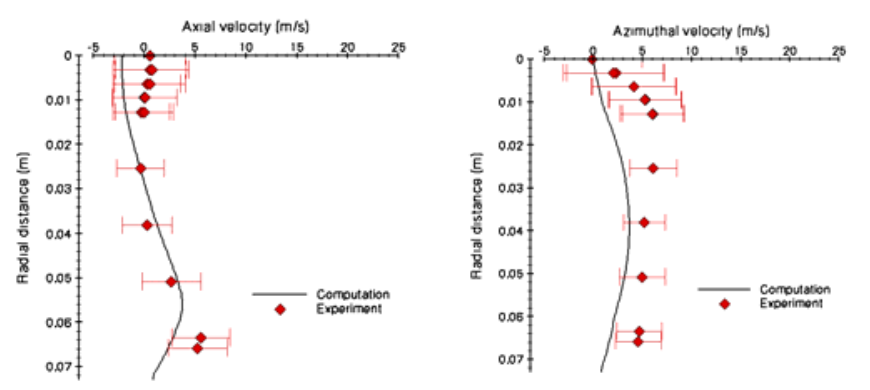

Fig. 12. Non-reacting Flow: Axial and azimuthal velocity components at $x=152.4 \mathrm{~mm}$

\section{Horizontal bars are experimental velocity fluctuations about the mean}

$50 \%$ confidence interval about the mean, indicating that if another measurement is made at the same point, there is only $50 \%$ chance that the measured data will fall within the same velocity fluctuation band. Considering the width of the velocity fluctuation bars, it is obvious that the computed results predict the experimental data quite reasonably.

\section{REACTING FLOW SIMULATION}

The non-reacting solution is used to initiate the reacting flow calculation. The Magnussen and Hjertager [8] model is used to account for the turbulence combustion.

Figure 13 is an axial cross section showing the computed axial velocity contours and the axial velocity profiles for both the computed and the measured data throughout the flowfield. No experimental data are reported at farther downstream since the flow was found to have little structure past $300 \mathrm{~mm}$. No experimental data are either reported at planes between 200 and $300 \mathrm{~mm}$, since this region was not accessible to the LDV optics during the experiment [9].

The axial velocity is high in the air stream and the air jet quickly spreads toward the combustor wall. The central recirculation zone around the centerline with a length approximately equal to the diameter of the combustor is maintained. Furthermore, recirculation is also formed in the corner region. These recirculation zones are well captured by the simulation. Comparing this figure with Fig. 9, several differences can be observed between these two flows.

In the reacting flow calculation, the heat release causes the axial velocity to be higher than that of the non-reacting flow. The central re-circulation zone is bigger in the non-reacting flow and contracts in the reacting flow. Furthermore, the nonreacting flow exhibits unsteadiness in terms of shape and location of the swirl cone and the re-circulation zone. In the reacting flow, smaller re-circulation region forms in the corner region of the entrance to the tailpipe. In the non-reacting flow, the central re-circulation zone penetrates too far upstream, whereas in the reacting flow, it is lifted from the fuel nozzle. The air jet also spreads more quickly in the non-reacting flow than in the reacting case.

Figure 14, shows the same axial cross-section, but showing the azimuthal velocity distribution on the top half, and the radial profiles on the bottom. The red diamond symbols are the measured values and the black solid lines are the computed ones. Unlike the non-reacting flow, the first station of $\mathrm{x}=$ $4.5 \mathrm{~mm}$ is predicted with more accuracy in the reacting flow. For all other stations, the predicted results range from good to excellent.
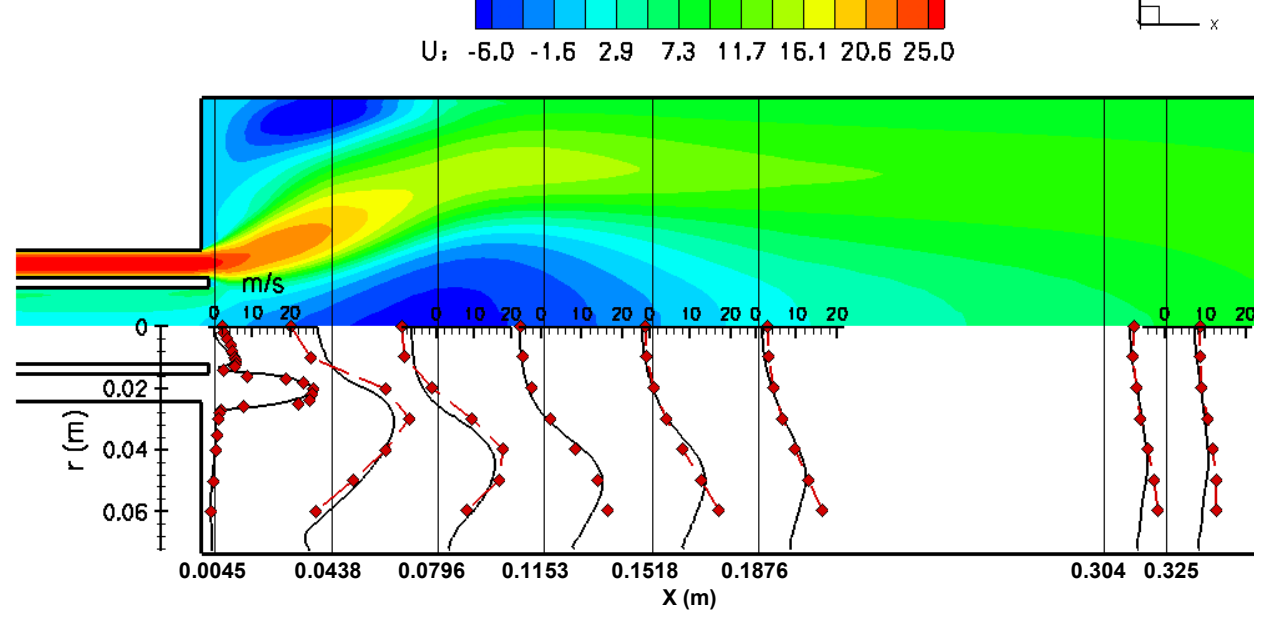

Fig.13. Reacting flow: axial velocity 
Figures 15 and 16 are enlarged line plots of axial and radial velocities at stations of $x=3.5 \mathrm{~mm}$, and $x=4.5 \mathrm{~mm}$. The horizontal bars are the experimental velocity fluctuations about the mean and they are used as the $50 \%$ confidence interval about the mean. Considering the range of the measured velocity fluctuations, the predicted results compare very well with the experimental data.

Figure 17 shows contours of computed temperature distribution in the upper half and a radial profile of the computed and measured temperature at various stations in the lower half. From the temperature distribution, it is clear that the flame front is highly lifted from the fuel nozzle. The computed temperature contours show that the maximum temperature occurs in the central re-circulation zone. This is reported in Ref. [9] based on the measured carbon dioxide profiles.

The temperature is better predicted in the earlier stations. The prediction becomes worse in the flame front region and gets better toward the middle of the flame and downstream of the flame. The predicted results show the trend but over-predict the temperature for the downstream stations. This is partly due to the difficulty in accurately measuring the flame front and the flame shape. As discussed in Ref. [9], "in many regions of the flow, the flame front continually moves back and forth across the bead (of the thermocouple), exposing it to large fluctuations in temperature. Uncertainty regarding the averaging of this temperature variation is significant in the first third of the combustor." It should also be mentioned that the combustion model used in this reacting flow computation is the eddy breakup model of Magnussen, which is a very simplified model. With the chemistry model used being a one-step global kinetics having only three species fuel, oxidant, and products, the absence of the intermediate species, such as $\mathrm{OH}$, leads to over-prediction of temperature especially in the fuel-rich regions. In addition, the heat radiation effects are not simulated. Furthermore, the combustion chamber walls are cooled in the experiment, whereas the computational model uses adiabatic wall condition. These differences all contribute to the differences between the computed results and the experimental data.

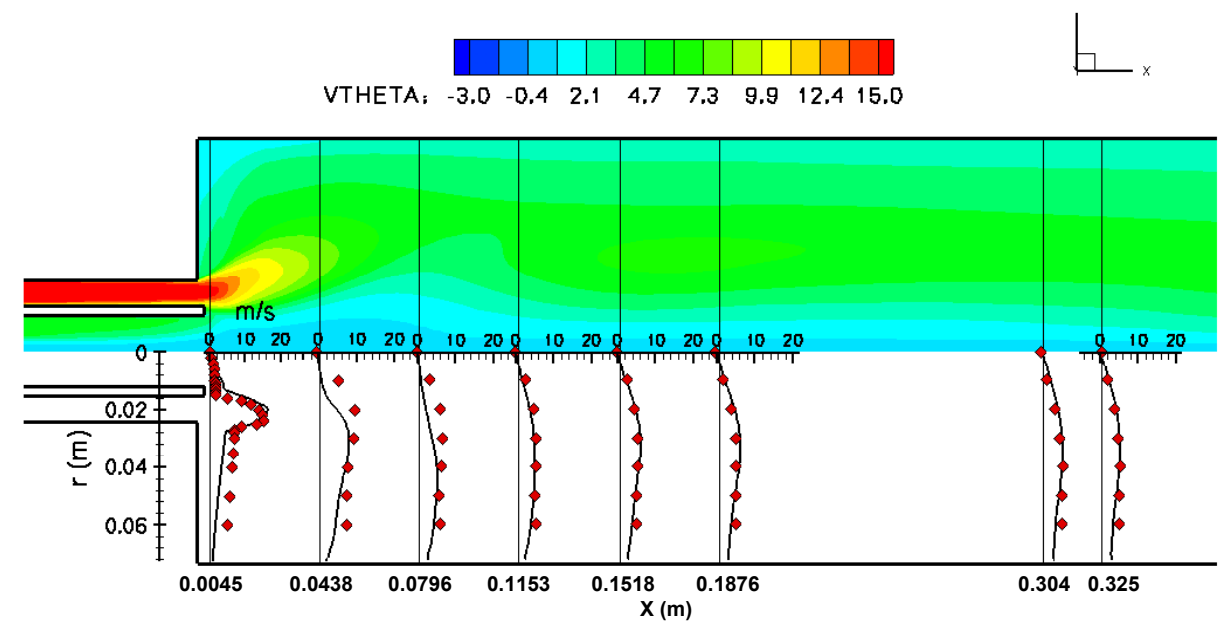

Fig. 14. Reacting flow: Azimuthal velocity
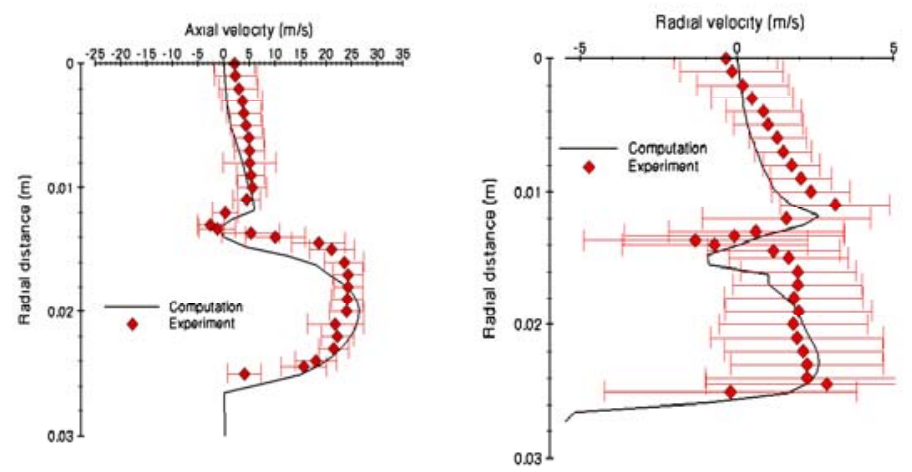

Fig. 15. Reacting flow: Axial and radial velocity components at $x=3.5 \mathrm{~mm}$

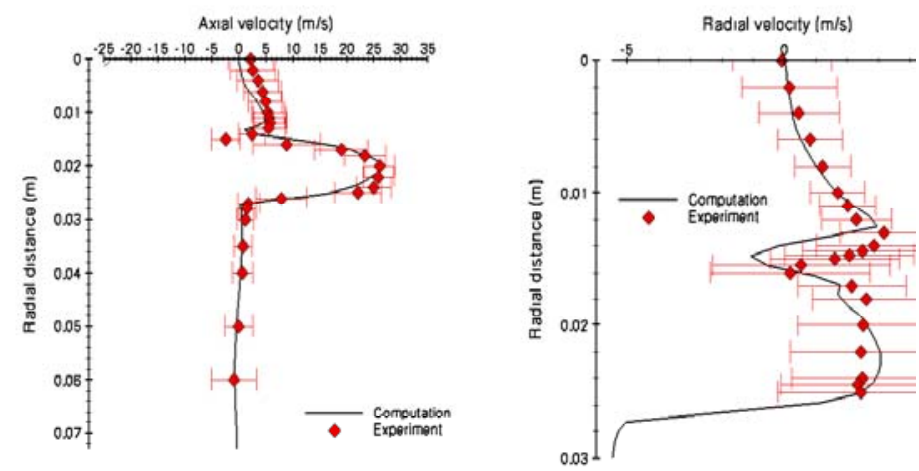

Fig. 16. Reacting flow: Axial and radial velocity components at $x=4.5 \mathrm{~mm}$ 


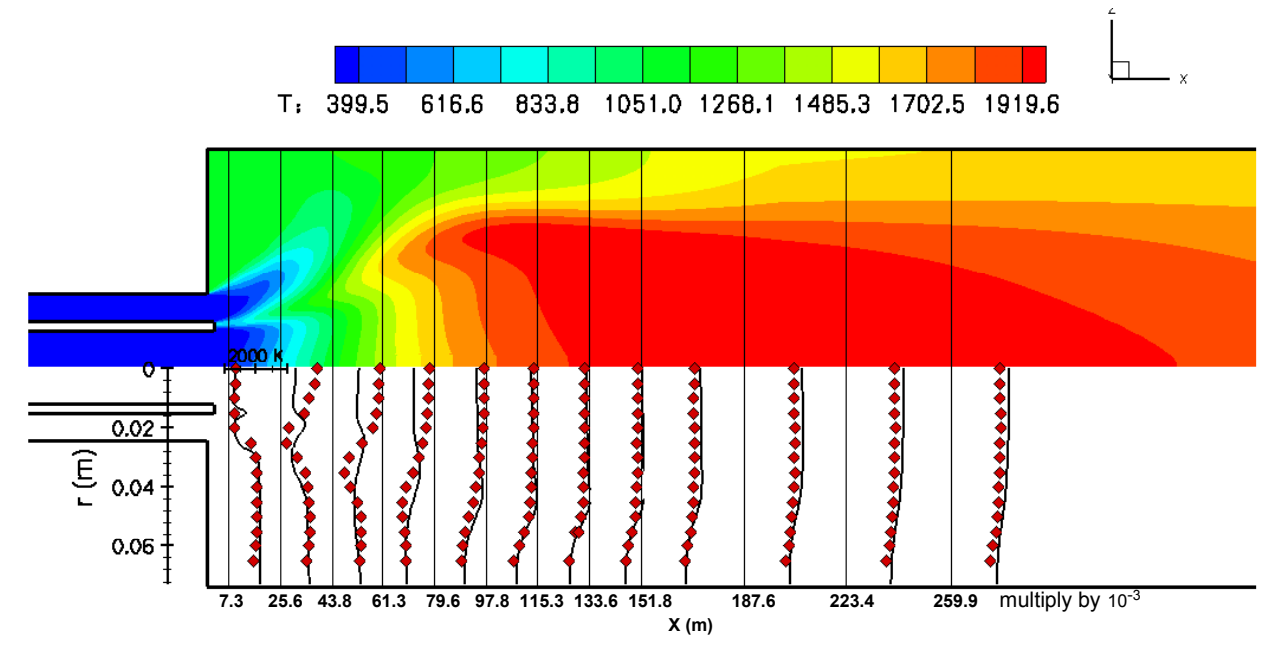

Fig. 17. Temperature contours $\&$ radial profiles

Figure 18 shows the mass fraction distributions of the oxidizer (i.e. air), the fuel, and the product. Oxidizer is highest in the air nozzle and along the air stream. The dashed blue line in the fuel plot shows the equivalence ratio contour of one. This is the line along which the stoichiometric amount of the oxidizer is present. The fuel mass fraction shows that most of the fuel is burned, and none left to be convected downstream. Central region of the combustor is primarily filled with the products.
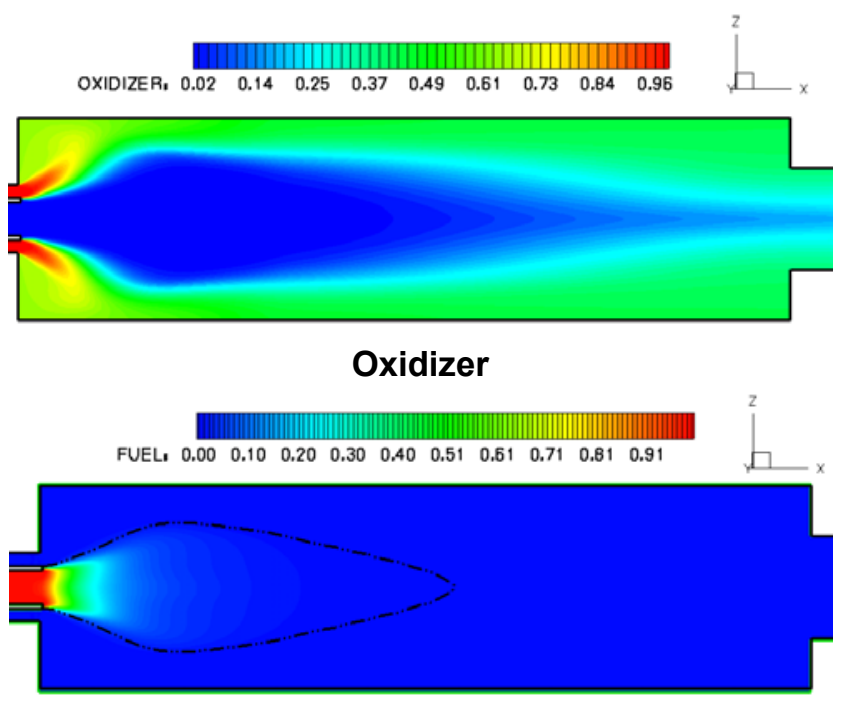

Fuel

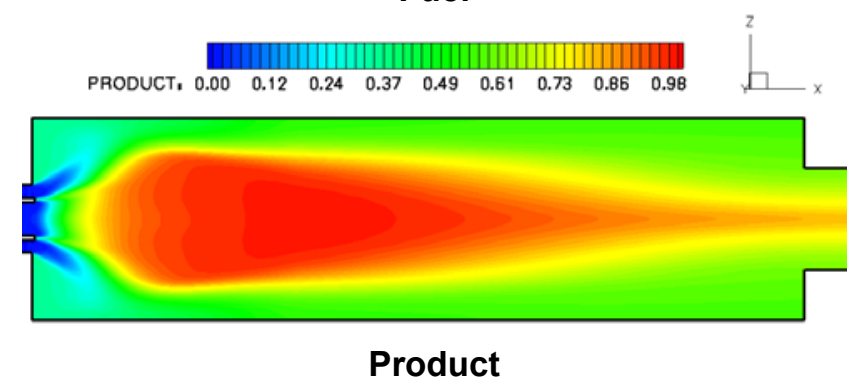

Fig. 18. Oxidizer, fuel, and product mass fractions

\section{SUMMARY AND CONCLUSIONS:}

Any simulation code used for design and analysis of realworld gas turbine combustors is required to predict the flow features and the flow quantities associated with these devices with reasonable accuracy and in a reasonable time frame.

An experimental model gas turbine combustor exhibiting the typical flow features associated with gas turbine combustors is numerically modeled to demonstrate the modeling capabilities of a computer code in predicting the flow characteristics of these combustors.

To minimize the overall turnaround time, unstructured grids are used for the discretization of the partial differential equations and parallel computing system is employed to perform the calculations.

The numerical simulation solves RANS equations together with a cubic non-linear k-epsilon turbulence model. The simple and less CPU intensive combustion model of Magnussen and Hjertager is used to model the turbulent combustion.

The simulation is conducted for the full $360^{\circ}$ geometry, encompassing twelve fuel channels and twelve air channel swirlers.

To compensate for the numerical swirl decay, the location of the flow swilrlers is adjusted along the inlet passage.

Results of the simulation demonstrate that the code can predict the essential features of the gas turbine combustors such as the compact re-circulation zone near the tip of the fuel nozzle, corner re-circulation zones, and the lifted flame with reasonable accuracy. In addition, comparisons of the computed velocity components with the experimental data show good agreements for both the non-reacting case as well as for the reacting one.

The CPU time per iteration per element is 80 microseconds for the non-reacting case and 90 microseconds for the reacting case.

Numerical simulation of chemically reacting flows is complex and CPU intensive. The simple turbulent combustion model used in the calculation presented in this paper yields a relatively good description of a reacting flow, helpful in the initial design of combustors. For the prediction of the concentration of $\mathrm{CO}$ and NOx, a more advanced turbulent 
combustion model involving finite rate chemistry is needed. Depending on the number of species used in the chemistry model and the model utilized for the turbulence chemistry interaction, the turnaround time could significantly be more than that reported in the present paper.

\section{REFERENCES}

[1] Quealy, A., 2002, "National Combustion Code Parallel Performance Enhancements," AIAA Paper No. 2002-3706.

[2] Shih, T.-H., Norris, A., Iannetti, A., Marek, J., Liu, N.-S., Smith, T., Povinelli, L. A., (2001), "Study of Hydrogen/Air Combustor Using NCC," AIAA Paper No. 2001-0808.

[3] Norris, A.T., 1997, “Automated Simplification of Full Chemical Mechanisms, AIAA Paper No. 97-3115.

[4] Norris, A.T., 1998 "Automated Simplification of Full Chemical Mechanisms-Implementation in National Combustion Code," AIAA Paper No. 98-3987.

[5] Shih, T.-H., Chen, K.-H., and Liu, N.-NS., 1998, “A NonLinear K-epsilon Model for Turbulent Shear Flows," AIAA Paper 98-3983.
[6] Liu, N.-S., "On the Comprehensive Modeling and Simulation of Combustion Systems," AIAA 2001-0805, 39 AIAA Aerospace Sciences Meeting \& Exhibit, 8-11 January 2001 / Reno, NV.

[7] Ryder, R. C., "The baseline Solver for the National Combustion Code," AIAA Paper 98-3853, July 1998, Cleveland, $\mathrm{OH}$.

[8] Magnussen, B.F., and Hjertager, B. H., 1977, “On Mathematical Modeling of Turbulent Combustion with Special Emphasis on Soot Formation and Combustion," Sixteenth Symposium (International) on Combustion, The Combustion Institute, pp. 719-729

[9] Bowman, C.T., Edwards, C.F., Gerdes J.C., Pitsch, H., Printz, F.B., 2002, "Active Control of Combustion Instability in Air-Breathing Propulsion Systems - A Computational and Experimental Program," Department of Mechanical Engineering, Stanford University, Final Technical Report, NASA-Glenn Grant No. NAG 2-1219. 


\begin{tabular}{|c|c|}
\hline \multicolumn{2}{|c|}{ REPORT DOCUMENTATION PAGE } \\
\hline \multicolumn{2}{|c|}{$\begin{array}{l}\text { Public reporting burden for this collection of information is estimated to average } 1 \text { hour per response, including the time for reviewing instructions, searching existing data sources } \\
\text { gathering and maintaining the data needed, and completing and reviewing the collection of information. Send comments regarding this burden estimate or any other aspect of thi } \\
\text { collection of information, including suggestions for reducing this burden, to Washington Headquarters Services, Directorate for Information Operations and Reports, } 1215 \text { Jefferson } \\
\text { Davis Highway, Suite 1204, Arlington, VA 22202-4302, and to the Office of Management and Budget, Paperwork Reduction Project (0704-0188), Washington, DC 20503. }\end{array}$} \\
\hline 1. AGENCY USE ONLY (Leave blank) & \begin{tabular}{|c|c|} 
2. REPORT DATE & 3. \\
August 2005 &
\end{tabular} \\
\hline \multicolumn{2}{|c|}{$\begin{array}{l}\text { Numerical Prediction of Non-Reacting and Reacting Flow in a Model Gas } \\
\text { Turbine Combustor }\end{array}$} \\
\hline \multicolumn{2}{|c|}{$\begin{array}{l}\text { 6. AUTHOR(S) } \\
\text { Farhad Davoudzadeh and Nan-Suey Liu }\end{array}$} \\
\hline $\begin{array}{l}\text { 9. SPONSORING/MONITORING AGEI } \\
\text { National Aeronautics and Sp } \\
\text { Washington, DC 20546-00 }\end{array}$ & $\begin{array}{l}\text { NAME(S) AND ADDRESS(ES) } \\
\text { Administration }\end{array}$ \\
\hline
\end{tabular}

\section{SUPPLEMENTARY NOTES}

Prepared for the Turbo Expo 2004 sponsored by the American Society of Mechanical Engineers, Vienna, Austria, June 14-17, 2004. Farhad Davoudzadeh, University of Toledo, 2801 W. Bancroft Street, Toledo, Ohio 43606, e-mail: Farhad.Davoudzadeh-1@nasa.gov; and Nan-Suey Liu, e-mail: Nan-Suey.Liu-1@nasa.gov, NASA Glenn Research Center. Responsible person, Farhad Davoudzadeh, organization code RTB, 216-433-8876.

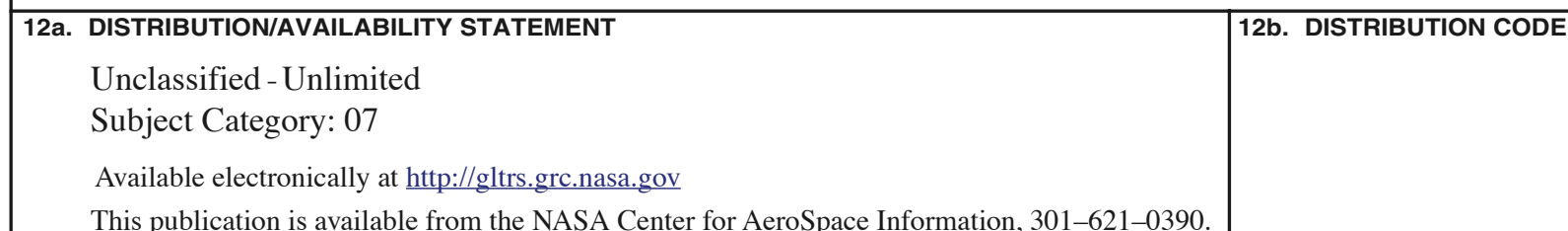

\section{ABSTRACT (Maximum 200 words)}

The three-dimensional, viscous, turbulent, reacting and non-reacting flow characteristics of a model gas turbine combustor operating on air/methane are simulated via an unstructured and massively parallel Reynolds-Averaged Navier-Stokes (RANS) code. This serves to demonstrate the capabilities of the code for design and analysis of real combustor engines. The effects of some design features of combustors are examined. In addition, the computed results are validated against experimental data.

\begin{tabular}{|c|c|c|c|}
\hline 14. SUBJECT TERMS & & & $\begin{array}{c}\text { 15. NUMBER OF PAGES } \\
16 \\
\end{array}$ \\
\hline NSN 7540-01-280-5500 & & & $\begin{array}{l}\text { andard Form } 298 \text { (Rev. 2-89) } \\
\text { scribed by ANSI Std. Z39-18 } \\
-102\end{array}$ \\
\hline
\end{tabular}



